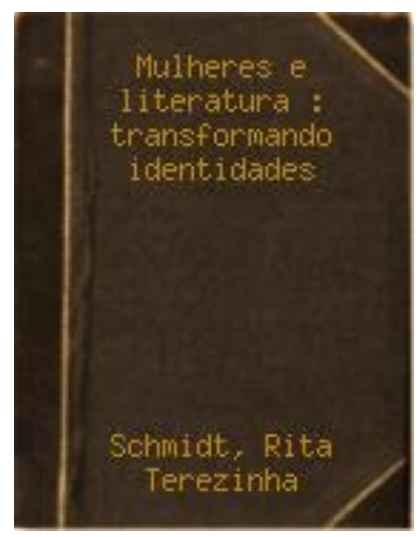

\title{
A voz da multiplicidade no reconhecimento da literatura feminina: leituras de Rita Schmidt
}

The voice of multiplicity in the recognition of feminine literature: readings by Rita Schmidt

\section{Amanda L. Jacobsen de Oliveira ${ }^{1}$ Juliana Prestes de Oliveira ${ }^{2}$ Anselmo Peres Alós ${ }^{3}$}

Resumo: Falar do político e do social implica considerar as relações em seu contexto. Por isso, diante das ocorrências atuais no âmbito nacional (envolvendo questões de gênero e direitos das mulheres), ainda que publicado em 1997, o livro Mulheres e Literatura: (Trans)Formando Identidades, organizado por Rita Terezinha Schmidt, mostra sua relevância e atualidade, uma vez que pautas que pareciam seguir para um caminho da resolução pertinente, agora, infelizmente, aparentam retroceder nesse processo. Assim, essa resenha procura discorrer sobre as variadas vozes reunidas por Rita Schmidt para refletir acerca da mulher no contexto literário e cultural, promovendo um diálogo que demonstra a complexidade e multiplicidade pertinentes ao tema discutido.

Palavras-chave: Mulher. Rita Schimidt. Identidade. Crítica Feminista.

Abstract: When talking about the politic and the social we need to consider the relationships within its context. Thus, in front of national current happenings (surrounding gender and women rights issues), even though it has been published in 1997, Rita Terezinha Schmidt's Mulheres e Literatura: (Trans)Formando Identidades, shows its relevance and contemporaneity once that guidelines that have seemed to go forward in direction of pertinent resolutions now, unfortunately, seem to move back in this process. Therefore, in this review, we talk about the many voices reunited by Rita Schmidt to think about woman in literary and cultural context, raising a dialogue to show the pertinent complexity and multiplicity to the discussed theme.

Keywords: Woman. Rita Schmidt. Identity. Feminist Criticism.

\footnotetext{
1 Amanda L. Jacobsen de Oliveira é mestra e doutoranda em Letras-Literatura pelo Programa de PósGraduação em Letras da Universidade Federal de Santa Maria, PPG-Letras/UFSM. Endereço: Rua Lamartine Babo, 560, Camobi, Santa Maria-RS, 97105-230. Email: amandajacobsen.o@ gmail.com

2 Juliana Prestes de Oliveira é mestra em Letras-Literatura pelo Programa de Pós-Graduação em Letras da Universidade Federal de Santa Maria, PPG-Letras/UFSM. Atualmente é acadêmica do curso de graduação de Licenciatura em Teatro e revisora pedagógica e linguística instrucional no NEaD CETISM, da mesma instituição. Endereço: Rua Lamartine Babo, 560, 97105-230, Camobi, Santa Maria-RS. Email: jprestesdeoliveira@gmail.com

3 Anselmo Peres Alós é professor adjunto na Universidade Federal de Santa Maria, UFSM. Docente Permanente do PPG-Letras, da mesma instituição. Endereço: Av. Roraima, n. 1000, Cidade Universitária, Camobi, Santa Maria - RS, 97105-900. Email: anselmoperesalos@ gmail.com.
} 
Falar de mulher(es) e literatura é falar de mulheres na/da/de e sobre a literatura: a mulher envolvida na literatura como autora, personagem e/ou crítica/teórica. Em um primeiro momento, essas considerações podem parecer, aparentemente, simples; entretanto, cada um desses lugares é representativo para as personas femininas que seguem reconhecendo e assumindo (ou sendo resgatadas em) diferentes facetas em uma sociedade majoritariamente patriarcal. Nesse sentido, é relevante perceber as peculiaridades referentes a cada espaço dessas atividades onde se resgata a presença feminina.

Em Mulheres e Literatura: (Trans)Formando Identidades (1997), Rita Terezinha Schmidt reúne discussões que percorrem a reflexão acerca da mulher no contexto literário. Ao convocar variadas vozes provindas de diferentes contextos, Schmidt promove um diálogo que demonstra $\operatorname{logo}$ em sua constituição a complexidade e multiplicidade provinda do tema discutido. A pluralidade como essência do trabalho referido ilustra bem o atual cenário da(s) teoria(s) e crítica(s) feminista(s), diante da sua variedade de perspectivas e possibilidades. Sendo assim, os autores contemplados no volume conseguem fornecer uma ampla gama de temas e leituras que não se encerram e não se esgotam; pelo contrário, podem instigar o leitor a ampliar a reflexão abrangendo outras escritoras, através de embasamentos diversificados.

A obra tem sua base no âmbito do Grupo de Trabalho "A mulher na literatura", da ANPOLL, e é representativa do gesto intelectual de resistência que o caracteriza, com a intenção de desestabilizar o conhecimento hegemônico, revelando o estabelecimento ideológico desse e buscando a reescritura das identidades femininas nesse contexto. Para isso, o livro foi dividido em quatro partes temáticas, que contemplam ensaios de autores provindos de diferentes instituições.

A primeira parte traz ensaios que abordam concepções críticas e teóricas feministas múltiplas. Em um conjunto de capítulos assinados por Nara Araújo, Darlene J. Sadlier, Susana Bornéo Funck e Márcia Hoppe Navarro, o texto parte do foco feminista na literatura caribenha, ilustrando a necessidade de se considerar a dinâmica de raça, gênero e nação, pensando o seu entrecruzamento. Posteriormente, Sadlier comenta as mudanças de foco do feminismo e mostra como se opera o conflito interno na discussão feminista, possibilitando ao leitor (mesmo que iniciante) entender as perspectivas divergentes e prolíficas que emergem nesse âmbito. Nos demais capítulos, destaca-se a participação dos homens no feminismo, discute-se o foco das pesquisas feministas 
(principalmente do grupo de pesquisa acima referido), e acompanha-se o desenvolvimento da literatura feminina latino-americana, pensando principalmente a problemática advinda das diferenças a serem consideradas quando se trata da literatura em países de terceiro mundo.

Essa primeira parte da obra organizada por Rita Terezinha Schmidt funciona, então, quase como uma introdução às demais discussões que se seguirão. Ela insere o leitor no contexto do pensamento feminista, fazendo-o pensar nas diferentes leituras possíveis diante de uma crítica múltipla e ainda em construção. É importante perceber ainda a escolha dos textos ali inseridos, uma vez que eles promovem um diálogo pertinente, conectado através de nomes ou teorias comuns entre si. Desse modo, acabase por ilustrar o modo como tais debates se interconectam.

A segunda parte do livro trabalha com a questão do cânone e sua relação com a literatura de autoria feminina. Nela, Constância Lima Duarte, Laura Cavalcante Padilha, Sylvia Paixão e Zahidé Lupinacci Muzart mostram o modo como a mulher foi repetidamente excluída ou apagada da história (literária, principalmente) e, dessa forma, tirou-se a sua possibilidade de aparecer em qualquer cânone. Por meio de suas palavras, percebemos a vivência feminina como sombra e complemento desses outros seres masculinos, sempre em destaque. Através de uma contextualização e exemplificação envolvente, as autoras inserem o leitor nesse âmbito, tornando impossível fechar os olhos diante do inegável detrimento da mulher escritora. Ademais, fica clara a maneira como inclusive os gêneros literários e os estilos identificados como femininos foram menosprezados. Seja no Brasil ou na África, fica clara a necessidade de questionamento diante da canonização literária, problematizando mesmo a sua constituição e base primeira.

A terceira parte do livro constitui-se por textos de Eduardo Assis Duarte, Ana Luiza Andrade, Lúcia Helena Vianna e Maria Consuelo Cunha Campos. As autoras e o autor discutem a relação entre cultura e gênero, mobilizada através de textos literários. Ao trazer o profícuo relacionamento entre literatura e cultura, seus ensaios conseguem estabelecer um diálogo polivalente que não privilegia um aspecto em detrimento do outro, mas considera-os em igualdade, mostrando a maneira como os textos literários podem trazer à tona importantes aspectos culturais que dizem respeito ao gênero. Dessa forma, percorrendo a literatura nordestina, os textos de Clarice Lispector e de Sônia Coutinho, entre outros, invoca-se o sobrenatural e o corpo feminino, bem como a imagem da mulher 
na sociedade patriarcal, além de refletir de modo consistente e claro (além de instrutivo) a categoria gender (em inglês), envolvida com os women's studies na América do Norte.

Por fim, a última parte da obra contempla importantes escritoras que seguem sendo resgatadas pela crítica. Algumas mais conhecidas, outras com nomes que começam a despontar. Percebemos então a necessidade, bem delineada e exercida pelos ensaios aqui convocados, em mencionar não somente os textos literários específicos de tais autoras, como também a pesquisa bibliográfica, uma vez que muitas dessas personalidades são ainda desconhecidas para o grande público. É nesse sentido que importa aqui destacar os textos de Aparecida Maria Nunes, Haydée Ribeiro Coelho, Sonia Maria C. Ayres Homena, Sérgio Costa, Elódia Xavier, Luiz Fernando Medeiros de Carvalho, Elaine Dorough Johnson, Izabel Brandão e Simone Caputo Gomes, ao pesquisarem as escritoras Clarice Lispector, Maria José de Queiroz, Hilda Hilst, Sônia Coutinho, Eliana Daffre, Liz Lochhead e várias escritoras caboverdianas - entre elas Eunice Borges, Yolanda Morazzo, Margarida Moreira e outras.

Ao observarmos essa obra organizada por Rita Schmidt, percebemos um encaminhamento que promove quase um afunilamento temático na estrutura do livro: ele inicia com temas mais gerais que promovem uma contextualização a respeito da crítica feminista; discute a problematização do cânone, a fim de poder inserir a literatura feminina/feminista e sobre a mulher nas discussões intelectuais; posteriormente, relaciona a literatura feminista com a cultura, ilustrando a necessidade dessa confluência para a efetivação dos debates, que passam então a agir e influenciar nas visões sociais e culturais vigentes. Por último, o foco passa para o texto literário especificamente, mostrando bem como se exercitam as pesquisas e investigações que resgatam essas escritoras esquecidas pela historiografia literária.

Por fim, com seu desenvolvimento, esse compêndio textual bem articulado consegue instigar o pensar a respeito da importância das universidades (e dos pesquisadores-professores) ao promover tais debates que envolvam os temas referidos e convoquem variadas vozes de escritoras para dentro de suas aulas e grupos de pesquisas. Exercício esse infindável e repleto de possibilidades, diante do número crescente de escritoras ainda a serem desveladas. E, nesse ímpeto, felizmente, como depreendemos do livro, aprendemos que " [...] quando se olha a cultura e a literatura sob o ponto de vista feminino, nada mais pode continuar igual a antes: nem a sociedade, nem a arte, nem a história" (PAIXÃO, 1997, p. 72). 


\section{Referências}

PAIXÃO, Sylvia. A literatura feminina e o cânone. In: SCHMIDT, Rita Terezinha. (Org.). Mulheres e literatura: (trans)formando identidades. Porto Alegre: Palloti, 1997. p. 71-78.

SCHMIDT, Rita Terezinha. (Org.). Mulheres e literatura: (trans)formando identidades. Porto Alegre: Palloti, 1997. 211 p. 


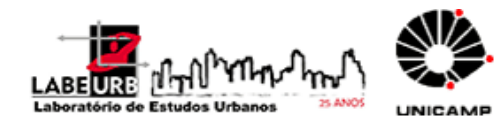

\section{Para citar essa obra:}

OLIVEIRA, Amanda L. Jacobsen de; OLIVEIRA, Juliana Prestes de; ALÓS, Anselmo Peres. A voz da multiplicidade no reconhecimento da literatura feminina: leituras de Rita Schmidt. In: RUA [online]. $n^{\circ}$. 23. Volume 2, p. 415 - 419 - e-ISSN 2179-9911 - Novembro/2017. Consultada no Portal Labeurb - Revista do Laboratório de Estudos Urbanos do Núcleo de Desenvolvimento da Criatividade.

http://www.labeurb.unicamp.br/rua/

Laboratório de Estudos Urbanos - LABEURB

Núcleo de Desenvolvimento da Criatividade - NUDECRI

Universidade Estadual de Campinas - UNICAMP

http://www.labeurb.unicamp.br/

\section{Endereço:}

LABEURB - LABORATÓRIO DE ESTUDOS URBANOS

UNICAMP/COCEN / NUDECRI

CAIXA POSTAL 6166

Campinas/SP - Brasil

CEP 13083-892

Fone/ Fax: (19) 3521-7900

Contato: http://www.labeurb.unicamp.br/contato 